\title{
What Do the Lips Say in Chronic Graft-Versus-Host Disease After Allogeneic Hematopoietic Stem Cell Transplantation? A Case Series
}

\author{
Anastazja Szlauer-Stefańska • Grażyna Kamińska-Winciorek
}

Received: March 23, 2021 / Published online: May 20, 2021

(c) The Author(s) 2021

\begin{abstract}
Introduction: Chronic graft-versus-host disease (cGvHD) affects around half of allogeneic hematopoietic stem cell transplantation (alloHSCT) recipients, with frequent involvement of the oral mucosa and lip vermillion, that clinically may resemble other autoimmune and inflammatory conditions. Our objectives were to define the dermoscopic patterns of lip vermilion in patients suffering from cGvHD and to compare the presentation with previously published dermoscopic presentations of other disease entities presenting on the lip vermillion.

Methods: A group of 16 patients diagnosed with cGvHD was assessed clinically and dermoscopically. The dermoscopic descriptions were made according to recent consensus on terminology of non-neoplastic disorders.

Results: Dermoscopy of vermillion frequently revealed dotted vessels that were found in all patients, while linear vessels without bends or branches were seen in 10 of them (62.5\%).
\end{abstract}

Anastazja Szlauer-Stefańska and Grażyna KamińskaWinciorek contributed equally.

A. Szlauer-Stefańska · G. Kamińska-Winciorek ( $\square)$ Department of Bone Marrow Transplantation and Onco-Hematology, Maria Sklodowska-Curie National Research Institute of Oncology (MSCNRIO), Gliwice Branch, Wybrzeże Armii Krajowej 15, 44-101 Gliwice, Poland e-mail: dermatolog.pl@gmail.com
Peripheral scale, mainly in white color $(13 / 16$, $81.2 \%$ ) was often present. Most striking features were parallel and perpendicular white lines, found in all patients. Other structures included brown dots and blood spots that were present in 10 patients $(62.5 \%)$. Four patients $(25.0 \%)$ had blurred vermillion border and in $8(50.0 \%)$ linear fissures or ulceration were found. Typical Wickham striae were found in $3(18.8 \%)$ patients.

Conclusions: The dermoscopic features observed in cGvHD affecting lip vermillion warrant differentiation with inflammatory (lichen planus), autoimmune (lichen sclerosus, discoid lupus erythematosus), precancerous (actinic keratosis, leukoplakia), and neoplastic diseases (squamous cell carcinoma), among others. Dermoscopy of lip vermillion might be an additional tool to visualize diagnostic mucoscopic features of cGvHD (lichen planuslike, lichen sclerosus-like lesions).

Keywords: Dermoscopy; Mucoscopy; Graftversus-host disease; Lip vermillion; Lichen planus-like; Lichen sclerosus-like 


\section{Key Summary Points}

Why carry out this study?

Involvement of oral mucosa is frequent in patients after allogeneic hematopoietic stem cell transplantation; however, no dermoscopic presentations of changes in the lip vermillion were published so far.

The study investigated the dermoscopic patterns found in lip vermillion in patients with chronic graft-versus-host disease (cGvHD).

\section{What was learned from the study?}

The dermoscopic features resemble those described in inflammatory, autoimmune, precancerous, and neoplastic diseases.

Dermoscopy of lip vermillion might be an additional tool to visualize diagnostic features of cGvHD, helping to establish the diagnosis without the need for biopsy.

\section{DIGITAL FEATURES}

This article is published with digital features, including a summary slide, to facilitate understanding of the article. To view digital features for this article go to https://doi.org/10.6084/ m9.figshare.14501277.

\section{INTRODUCTION}

Dermoscopy is a useful tool for rapid diagnosis and monitoring the response to treatment of various skin disorders, and the use of specific dermoscopy algorithms allows one to achieve high interobserver agreement $[1,2]$. Inflammatory dermatoses were also the subject of dermoscopic assessment [3, 4], and its use was recently reported in patients with graft-versus host disease (GvHD) after allogeneic hematopoietic stem cell transplantation (alloHSCT) [5-8].

The use of dermoscopy has also spread to the assessment of oral mucosa in so-called mucoscopy [9] and the dermoscopic patterns of labial mucosa according to age and sex [10] were previously described. Assessment of mucous membranes has its technical limitations, and is not always feasible, because existing dermoscopes are not well designed to explore the mucosa [11]. On the other hand, lip vermillion, a unique entity covered by specialized stratified squamous epithelium, a border between the skin and mucosa, is readily accessible by dermoscope, without need for technical modifications.

Oral GvHD occurs in $45-83 \%$ patients who develop chronic GvHD (cGvHD) [12], and encompasses a wide spectrum of clinical presentations, paralleling autoimmune and inflammatory conditions [12]. Lip vermilion is one of the locations scored for the presence of erythema, lichenoid changes, erosions, and ulcers in the course of cGvHD [12].

Our study aimed to investigate if the characteristic dermoscopic patterns exist on the lip vermillion in patients with cGvHD and if they resemble previously published inflammatory and autoimmune conditions presenting in this location.

\section{METHODS}

\section{Ethical Considerations}

The study protocol was approved by the Bioethics Committee of Maria SklodowskaCurie National Research Institute of Oncology, Gliwice Branch (KB/430 43/18). The study was performed in accordance with the Declaration of Helsinki. Informed consent for publication was obtained from all participants.

\section{Study Design}

In this case series study, 16 unselected consecutive patients aged over 18 years old, treated in the Bone Marrow Transplantation and Oncohematology Department in 2019, after alloHSCT with diagnosis of cGvHD according to 
National Institutes of Health (NIH) criteria [13], underwent clinical and dermoscopic assessment of lip vermillion. All dermoscopic images were captured and saved using a DermLite Cam (3Gen, LLC, Dana Point, California, USA) in polarized light, at tenfold magnification, and assessed independently by two study authorscertified dermoscopists (GK-W, AS-S). To compare the dermoscopic presentation with other diseases presenting on the lip vermillion we have performed the search in PubMed using the search terms dermoscopy OR dermatoscopy AND lip OR vermillion AND autoimmune OR inflammatory OR lichen planus OR lichen sclerosus OR discoid lupus erythematosus OR acitinic cheilitis (Table 2).

\section{Statistics}

Specific findings were considered present if both observers agreed. For the description of dermoscopic features, standardized terminology from recent dermoscopic consensus on non-neoplastic disorders was used [14].

\section{RESULTS}

Details of the patients, including transplant and dermoscopic characteristics, are given in Table 1. Dotted vessels were noted in all patients, while linear vessels without bends or branches were seen in 11 of them $(68.8 \%)$. Vessels were of unspecific $(14 / 16,87.5 \%)$ or clustered $(2 / 16,12.5 \%)$ distribution. Scale, mainly in white color $(13 / 16,81.2 \%)$, was distributed peripherally $(10 / 13,76.9 \%)$ or patchy $(3 / 13,23.1 \%)$. In all dermoscopic images white lines were found; most commonly they were parallel $(14 / 16,87.5 \%)$, sometimes accompanied by perpendicular or angulated lines. Other structures included brown dots $(6 / 16,37.5 \%)$, and blood spots were present in 10 patients $(62.5 \%)$. Four patients $(25.0 \%)$ had blurred vermillion border and in 8 (50.0\%) linear fissures or ulceration were found. Typical Wickham striae were found in $3(18.8 \%)$ patients.

\section{DISCUSSION}

Changes in the lip vermillion found in own observation in patients with chronic GvHD resemble lichen planus, lichen sclerosus, discoid lupus erythematosus, and actinic cheilitis (summary presented in Table 2). There is scarce literature on dermoscopic characteristics of lip vermillion in selected inflammatory or autoimmune dermatoses, mainly in the form of case reports or case series, that we discuss below.

\section{Lichen Planus}

Lichen planus on the lip has a specific signWickham striae-which is considered to be a marker of active disease [15]. Various patterns of those shiny whitish structures were described, including reticular, linear, and circular [15]. Its pathogenesis is equivocal-it is explained by the increase in granular cell layer in the epidermis by some authors and to the focal increase in the epidermal activity by others [15]. Wickham striae are usually seen on violaceous background, often accompanied by scaling, with dotted and linear peripheral vessels [15]. In our cohort, similar structures were seen in three patients suffering from lichen planus-like chronic GvHD (one of them is shown in Fig. 1a, b).

\section{Lichen Sclerosus}

The white, linear, dense homogenous area in long-standing lesions of lichen sclerosus in dermoscopy was suggested to correlate with the fibrosis affecting the upper dermis seen in histology [16]. In our patients, linear, white homogenous areas in biopsy-proven lichen sclerosus-like cGvHD were found (Fig. 1c, d). Dermoscopy of some patients demonstrated parallel and perpendicular white lines (Figs. 1e, f, $2 \mathrm{~g}, \mathrm{~h}$ ).

\section{Discoid Lupus Erythematosus}

In a study concerning mucosal and labial discoid lupus erythematosus the most common 
1426

Dermatol Ther (Heidelb) (2021) 11:1423-1434

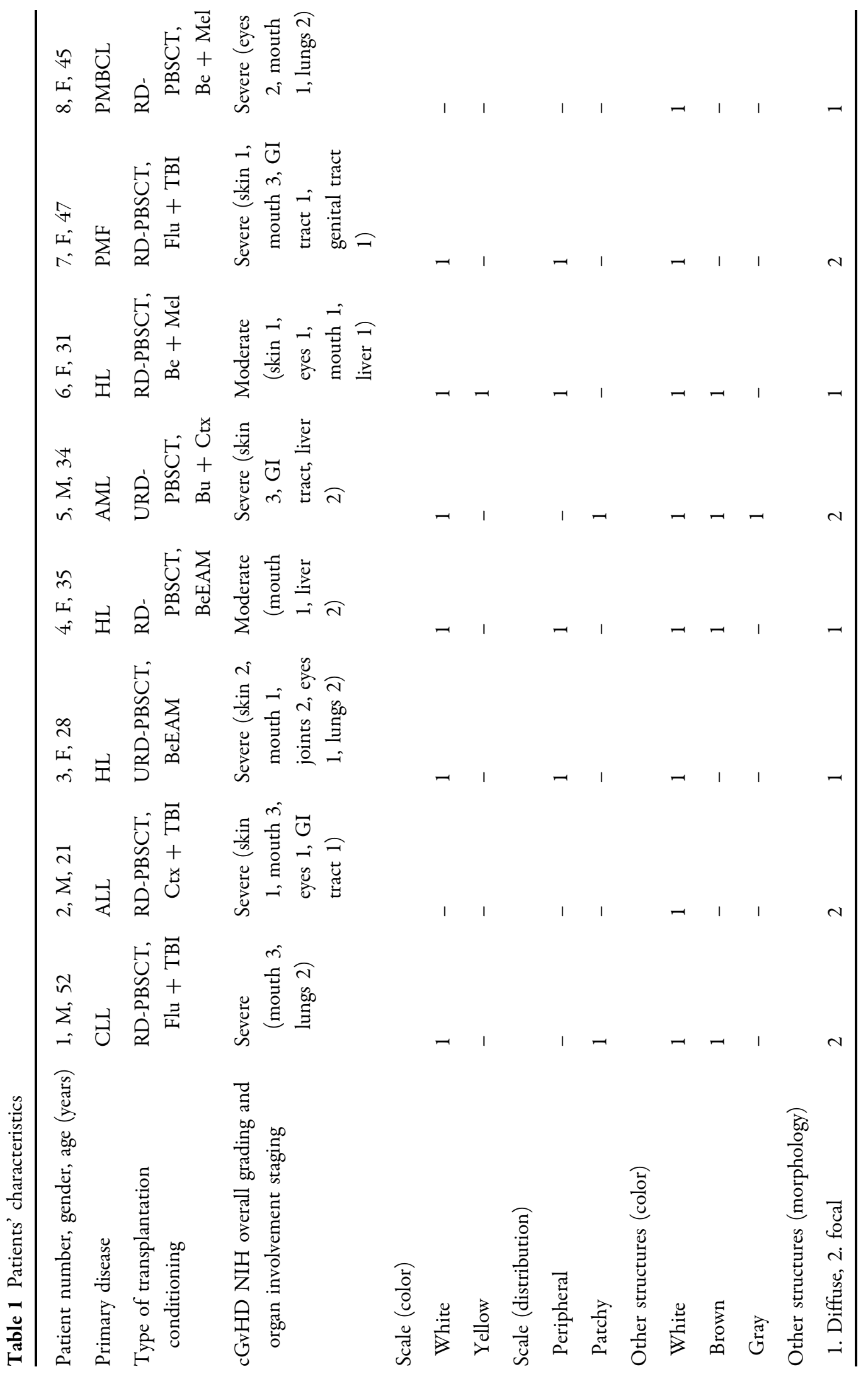

$\triangle$ Adis 


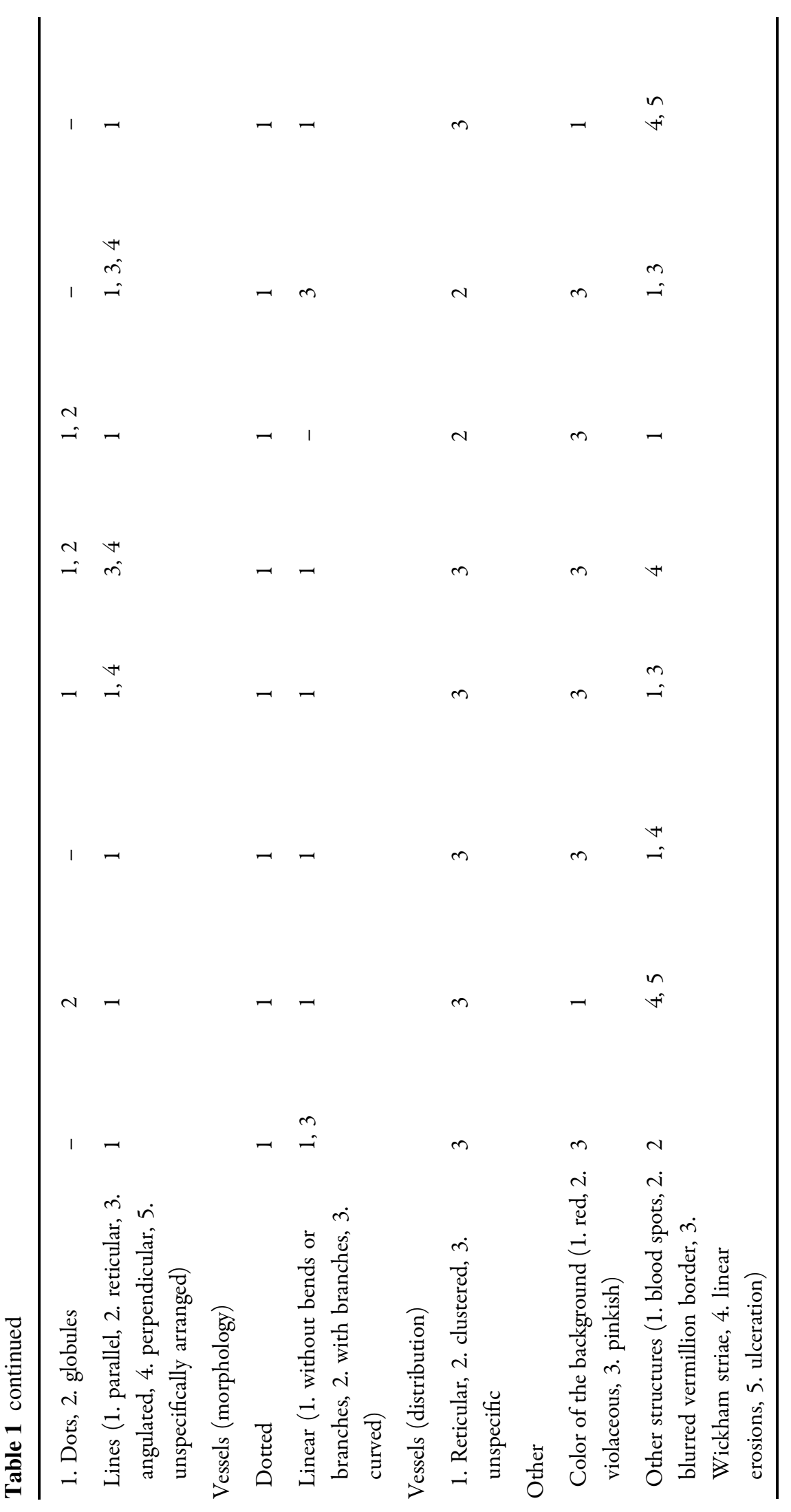




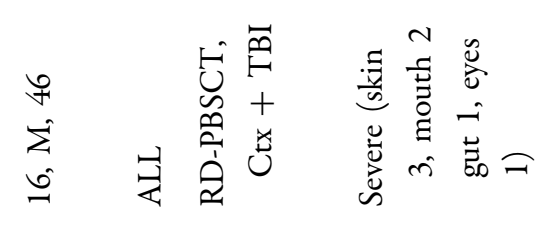

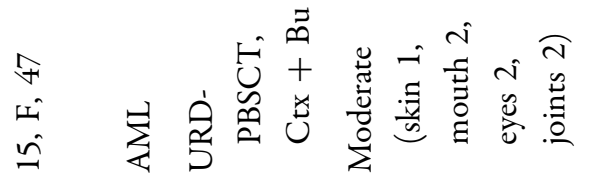

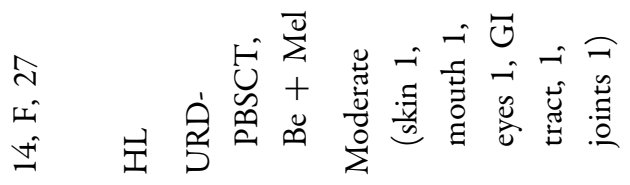

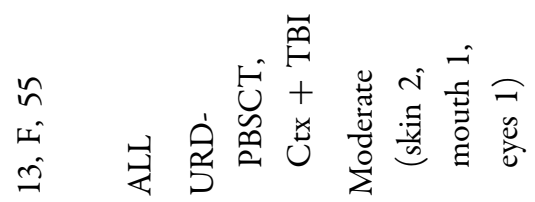

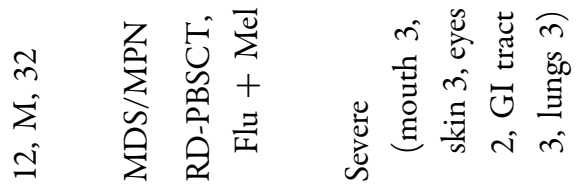

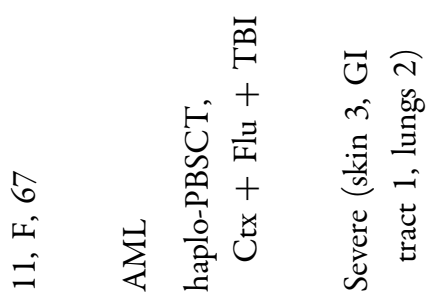

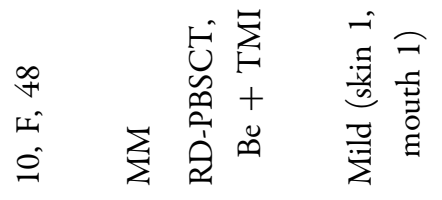

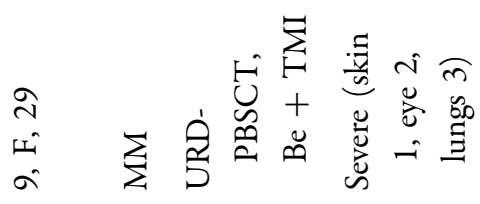

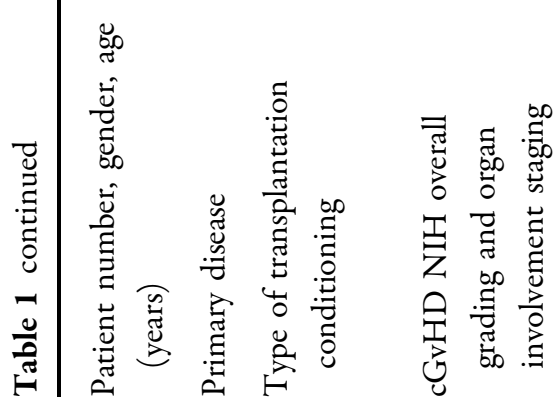

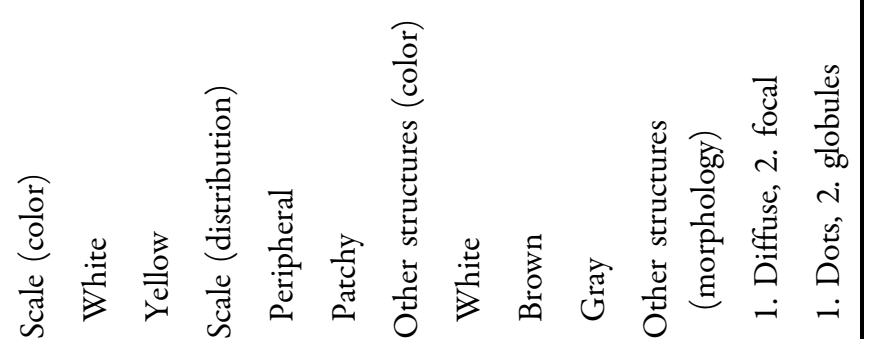




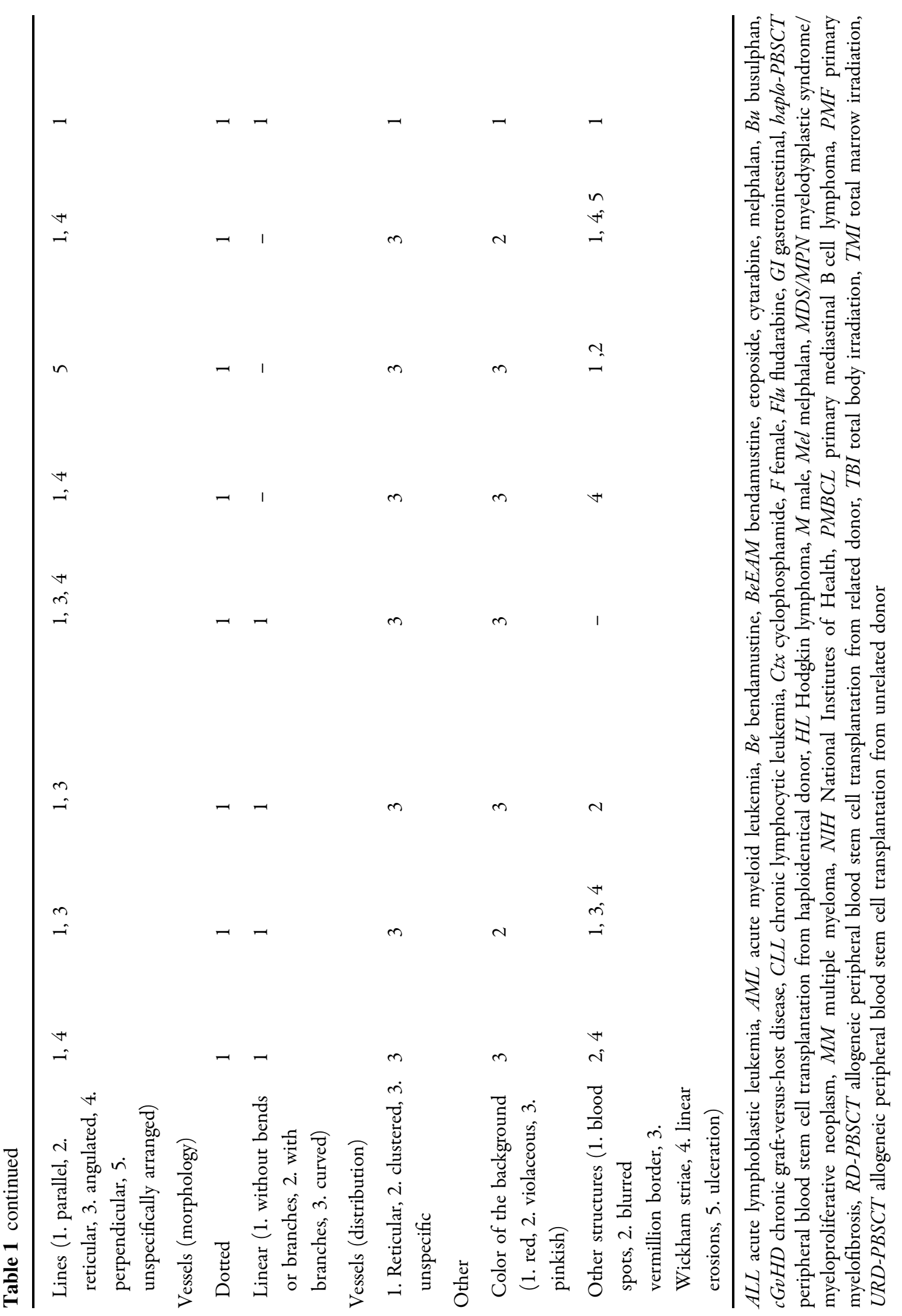


Table 2 Comparison of dermoscopic features of lip vermillion in selected entities and our cohort

\begin{tabular}{|c|c|c|}
\hline & Literature & Patients with cGvHD \\
\hline Lichen planus & $\begin{array}{l}\text { Wickham striae, usually on violaceous background, } \\
\text { often accompanied by scaling, with dotted and } \\
\text { linear peripheral vessels [13] }\end{array}$ & $\begin{array}{l}\text { Structures resembling Wickham striae were seen in } \\
\text { three patients suffering from lichen planus-like } \\
\text { chronic GvHD (one of them is shown on Fig. 1a, } \\
\text { b) }\end{array}$ \\
\hline Lichen sclerosus & $\begin{array}{l}\text { White, linear, dense homogenous areas that } \\
\text { correlate with the fibrosis affecting the upper } \\
\text { dermis seen in histology [14] }\end{array}$ & $\begin{array}{l}\text { Linear, white homogenous areas (Fig. 1c, d). } \\
\text { Parallel and perpendicular white lines (Fig. 1e, f) }\end{array}$ \\
\hline $\begin{array}{l}\text { Discoid lupus } \\
\text { erythematosus }\end{array}$ & $\begin{array}{l}\text { Late lesions-telangiectasia and white structureless } \\
\text { areas, brown pigment spots, blood spots, and } \\
\text { erosions [15] }\end{array}$ & $\begin{array}{l}\text { Brown dots, linear erosions, and blood spots were } \\
\text { also frequently reported in our study (Fig. 1g, h) }\end{array}$ \\
\hline Actinic cheilitis & $\begin{array}{l}\text { Pale, flaking or scaly lips, areas of erythema, chronic } \\
\text { ulcerations and erosions, white plaques, blurring } \\
\text { of the lip vermillion border, and vermillion } \\
\text { atrophy [16] }\end{array}$ & $\begin{array}{l}\text { Scaling, white structures, blurred vermillion border, } \\
\text { linear erosions, and ulceration (Fig. } 2 \mathrm{a}-\mathrm{d} \text { ) }\end{array}$ \\
\hline Other features & \multicolumn{2}{|c|}{$\begin{array}{l}\text { Multiple yellow white spots resembling Fordyce spots (Fig. 2e, f). Accompanied by exophytic mucosal } \\
\text { lesions (histopathology revealed sclerotic-type cGvHD with GvHD-associated angiomatosis) }\end{array}$} \\
\hline
\end{tabular}

${ }_{c} G v H D$ chronic graft-versus-host disease

dermoscopic signs, present in over half of the patients, were follicular keratotic plugs and scales [17]. In early lesions they were accompanied by perifollicular white halos and in late lesions by telangiectasia and white structureless areas, with additional features present on the lip-brown pigment spots, blood spots, and erosions. Brown dots, linear erosions, and blood spots were also frequently reported in our study (Fig. 1g, h).

\section{Actinic Cheilitis}

Oncological vigilance is of extreme importance in patients after alloHSCT, and oral GvHD is a known risk factor of lip squamous cell carcinoma (SCC). SCC can be preceded by actinic cheilitis that may present in many forms, including pale, flaking, or scaly lips, areas of erythema, chronic ulcerations and erosions, white plaques, blurring of the lip vermillion border, and vermillion atrophy [18]. In our patients the following features were often found: scaling, white structures, blurred vermillion border, linear erosions, and ulceration (Fig. 2a-d).

\section{Others}

Dermoscopy of Fordyce spots, which may arise in healthy individuals, showed yellow lobules surrounded by nonarborizing vessels [19]. In one of our patients suffering from cGvHD, multiple yellow white spots occurred after transplantation, resembling Fordyce spots (Fig. 2e, f). These were accompanied by exophytic mucosal lesions. In this case histopathology revealed sclerotic-type GvHD with GvHD-associated angiomatosis.

\section{Oral Involvement in cGvHD}

Despite the progress in alloHSCT procedures, the prevalence of cGvHD continues to grow [20], and it remains one of the main causes of 


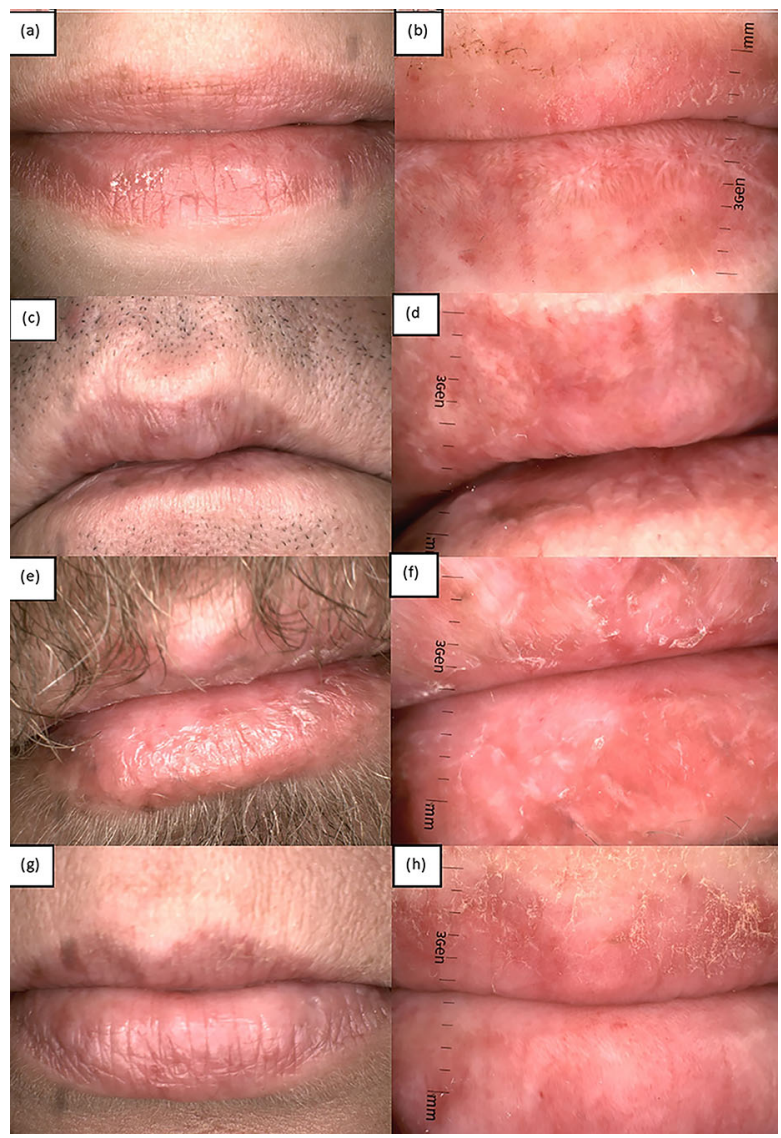

Fig. 1 Clinical (a, c, e, g) and dermoscopic (polarized light, tenfold magnification) (b, d, f, h) presentations of lip vermillion in patients with chronic graft-versus-host disease (cGvHD). a (Patient 4). In the clinical picture focal hyperpigmentation and depigmentation areas and shiny whitish linear scarring-like structures were noted. b (Patient 4). Dermoscopy showed white peripheral scale, multiple diffuse brown dots, white parallel and perpendicular shiny lines. Dotted and linear vessels, blood spots, and Wickham striae are also visible. c (Patient 1). In clinical examination of atrophic lips focal hyperpigmented areas were seen. $\mathbf{d}$ (Patient 1 ). Dermoscopy revealed patchy white scale, parallel brown and white lines, dotted, linear without bends, and linear curved vessels of unspecific distribution, blurred vermillion border. e ( $\mathrm{Pa}-$ tient 12). Clinical presentation of dried, flaking lips with multiple brown hyperpigmented areas. f (Patient 12). Dermoscopy showed white peripheral scale, white and brown parallel, angulated, and perpendicular lines, brown dots, dotted and linear vessels. $\mathbf{g}$ (Patient 6). In the clinical picture dry lip vermillion, hyperpigmentation, and whitish areas were noted. h (Patient 6). Dermoscopy revealed white and yellow peripheral scale, diffuse brown and white parallel lines, brown dots, white globules, dotted vessels of unspecific distribution, and blood spots

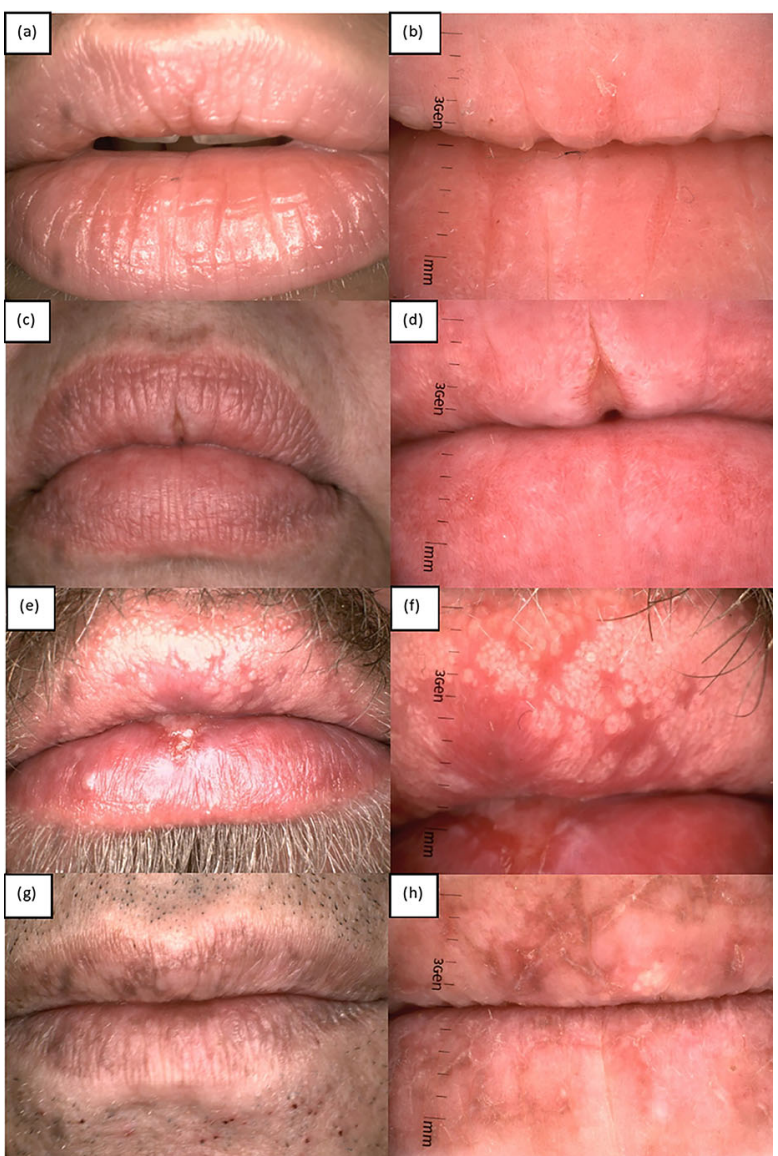

Fig. 2 Clinical (a, c, e, g) and dermoscopic (polarized light, tenfold magnification) (b, d, $\mathbf{f}, \mathbf{h})$ presentations of lip vermillion in patients with cGvHD. a (Patient 13). In the clinical picture chapped lips were seen. b (Patient 13). Dermoscopy showed white peripheral scale, white diffuse parallel and perpendicular lines, dotted vessel of unspecific distribution, and multiple linear almost parallel erosions. c (Patient 8). Clinical presentation involved chapped lips and central linear ulceration. d (Patient 8). Dermoscopy showed short, white, diffuse parallel lines between numerous dotted and linear vessels, linear erosions, and ulceration. e (Patient 2). In the clinical picture whitish, cobblestone-like areas covering all surfaces of the upper lip, ulceration, and several linear erosions were observed. f (Patient 2). Dermoscopy revealed focal white globules as a predominant feature, dotted and linear vessels, linear erosions, and ulceration. g (Patient 5). In the clinical picture multiple, hyperpigmented foci were seen. $\mathbf{h}(\mathrm{Pa}-$ tient 5). Dermoscopy revealed white patchy scale, brown and gray dots, white globules, and white and brown perpendicular and angulated lines with dotted and linear vessels. Linear erosions are also visible 
long-term mortality and morbidity for patients surviving for longer than 2 years after alloHSCT [21]. Oral cGvHD is clinically diagnosed by history, context, and clinical examination [12]. According to NIH criteria, lichen planus-like changes belong to diagnostic clinical signs for cGvHD, while erythematous and ulcerative changes are distinctive signs [13]. Oral lesions frequently accompany involvement of other organs and treatment is based on systemic therapy with local topical treatment including high-potency glucocorticosteroids and calcineurin inhibitors [12]. The differential diagnosis of oral changes in the late phase after alloHSCT includes cGvHD but also infectious and other immunological reactions such as Stevens-Johnson syndrome. Clinical history and exclusion of infection are of foremost importance. Histopathology may be not conclusive, as diffuse $\mathrm{T}$ cell infiltration was reported in the labial minor salivary glands and in the buccal mucosa in oral cGvHD, with other features including thickening of the epithelium, interface submucosal lymphocytic infiltrate, epithelial atrophy, and basal cell apoptosis and degeneration [12]. Such diffuse T cell infiltration has also been reported in autoimmune or chronic inflammatory diseases that clinically resemble cGvHD [12].

\section{CONCLUSIONS}

On the basis of the dermoscopic presentation, we found the following types of lip vermillion morphology in patients suffering from chronic GvHD: (1) lichen planus-like (with Wickham striae); (2) lichen sclerosus-like with predominance of linear, white homogenous areas; (3) resembling discoid lupus erythematosus with blood spots, brown dots, and erosions; (4) resembling actinic cheilitis with fissures and/or ulceration.

This case series presents the first insight into the dermoscopic features of lip vermillion in patients with cGvHD. The limitations of the observation include the small number of cases and lack of control group. Further prospective studies with dermoscopic pictures assessed by researchers blinded to diagnosis are needed to establish the diagnostic accuracy of dermoscopy of lip lesions in cGvHD.

All in all, while the clinical picture may be non-alarming, dermoscopy of the lip vermilion may show more, pointing to the diagnosis of cGvHD. Oral cavity involvement may be highly predictive of the presence of systemic cGvHD [12]; and if the diagnostic signs are present, histopathological examination is not needed to confirm the diagnosis of cGvHD [13]. Dermoscopy of lip vermillion might be an additional diagnostic tool that reveals those diagnostic features (lichen planus-like, lichen sclerosus-like lesions), sometimes subtle and not visible in naked eye examination, thus contributing important information to clinical assessment.

\section{ACKNOWLEDGEMENTS}

Funding. No funding or sponsorship was received for this study or publication of this article.

Authorship. All named authors meet the International Committee of Medical Journal Editors (ICMJE) criteria for authorship for this article, take responsibility for the integrity of the work as a whole, and have given their approval for this version to be published.

Authorship Contributions. Both authors (AS-S and GK-W) contributed equally to concept and study design, data acquisition, statistical analysis, literature review and writing of the manuscript.

Disclosures. Anastazja Szlauer-Stefańska and Grażyna Kamińska-Winciorek have nothing to disclose.

Compliance with Ethics Guidelines. The study protocol was approved by the Bioethics Committee of Maria Sklodowska-Curie National Research Institute of Oncology, Gliwice Branch (KB/430 43/18). The study was performed in accordance with the Declaration of Helsinki. The patients in this manuscript have given 
written informed consent to publication of their case details.

Data Availability. The datasets generated during and/or analyzed during the current study are available from the corresponding author on reasonable request.

Open Access. This article is licensed under a Creative Commons Attribution-NonCommercial 4.0 International License, which permits any non-commercial use, sharing, adaptation, distribution and reproduction in any medium or format, as long as you give appropriate credit to the original author(s) and the source, provide a link to the Creative Commons licence, and indicate if changes were made. The images or other third party material in this article are included in the article's Creative Commons licence, unless indicated otherwise in a credit line to the material. If material is not included in the article's Creative Commons licence and your intended use is not permitted by statutory regulation or exceeds the permitted use, you will need to obtain permission directly from the copyright holder. To view a copy of this licence, visit http://creativecommons.org/licenses/by$\mathrm{nc} / 4.0 /$.

\section{REFERENCES}

1. di Meo N, Stinco G, Bonin S, et al. CASH algorithm versus 3-point checklist and its modified version in evaluation of melanocytic pigmented skin lesions: the 4-point checklist. J Dermatol. 2016;43:682-5.

2. di Meo N, Damiani G, Vichi S, et al. Interobserver agreement on dermoscopic features of small basal cell carcinoma $(<5 \mathrm{~mm})$ among low-experience dermoscopists. J Dermatol. 2016;43:1214-6.

3. Errichetti E, Stinco G. Dermoscopy in general dermatology: a practical overview. Dermatol Ther. 2016;6:471-507.

4. Blum A, Fink C, Haenssle HA, et al. Inflammoscopy: dermatoscopy for inflammatory, infiltrating and infectious dermatoses: Indication and standardization of dermatoscopic terminology. Hautarzt. 2020;71:627-46.
5. Kaminska-Winciorek G, Czerw T, Kruzel T, Giebel S. Dermoscopic follow-up of the skin towards acute graft-versus-host-disease in patients after allogeneic hematopoietic stem cell transplantation. Biomed Res Int. 2016;2016:4535717.

6. Szlauer-Stefańska A, Kamińska-Winciorek G, Giebel S. Onychoscopy of non-infectious nail abnormalities in patients after allogeneic haematopoietic stem cell transplantation. J Eur Acad Dermatol Venereol. 2019;33:637-42.

7. Kaminska-Winciorek G, Zalaudek I, Mendrek W, et al. Dermoscopy of cutaneous graft-versus-hostdisease in patients after allogeneic hematopoietic stem cell transplantation. Dermatol Ther. 2020. https://doi.org/10.1007/s13555-020-00423-6.

8. Kamińska-Winciorek G, Szlauer-Stefańska A. Mucoscopy in acute graft-versus-host disease. Oral Dis. 2020. https://doi.org/10.1111/odi.13642.

9. Sakamaki H, Kondoh T, Takeda Y, et al. Development of contact mucoscopy for oral mucosal diseases; a preliminary report. J Jpn Soc Oral Mucous Membr. 2007;13:8-15.

10. Ayhan E, Öztürk M, An I, Araç E. Dermoscopy of oral labial mucosa according to age and sex in healthy adults: first observational dermoscopic study. Turk J Dermatol. 2019;13:135.

11. Jakhar D, Grover C. Innovative modification of the USB dermatoscope for mucoscopy. J Am Dermatol. 2017;78:e3-4.

12. Fall-Dickson JM, Pavletic SZ, Mays JW, Schubert MM. Oral complications of chronic graft-versushost disease. J Natl Cancer Inst Monogr. 2019;2019: 54-62.

13. Jagasia $\mathrm{MH}$, Greinix HT, Arora $\mathrm{M}$, et al. National Institutes of Health Consensus Development Project on criteria for clinical trials in chronic graftversus-host disease: I. The 2014 Diagnosis and Staging Working Group Report. Biol Blood Marrow Transplant. 2015;21:389-4011.

14. Errichetti E, Zalaudek I, Kittler H, et al. Standardization of dermoscopic terminology and basic dermoscopic parameters to evaluate in general dermatology (non-neoplastic dermatoses): an expert consensus on behalf of the International Dermoscopy Society. Br J Dermatol. 2020;182: 454-67.

15. Mathur M, Acharya P, Karki A, Kc N, Shah J, Jha A. Isolated lichen planus of lip: diagnosis and treatment monitoring using dermoscopy. Clin Case Rep. 2019;7:146-8. 
16. Apalla Z, Lallas A. Dermoscopy of atypical lichen sclerosus involving the tongue. J Dermatol Case Rep. 2012;6:57-8.

17. Salah E. Clinical and dermoscopic spectrum of discoid lupus erythematosus: novel observations from lips and oral mucosa. Int J Dermatol. 2018;57: 830-6.

18. Kibbi N, Suozzi KC, Ko CJ, Leffell DJ. Squamous cell carcinoma of the lip in a patient with graft-versushost disease. Dermatol Surg. 2019;45:1002-5.
19. Jakhar D, Kaur I. Mucoscopy of Fordyce's spots on lips. Indian Dermatol Online J. 2019;10:498.

20. Arai S, Arora M, Wang T, et al. Increasing incidence of chronic graft-versus-host disease in allogeneic transplantation: a report from the center for international blood and marrow transplant research. Biol Blood Marrow Transplant. 2015;21:266-74.

21. Wingard JR, Majhail NS, Brazauskas R, et al. Longterm survival and late deaths after allogeneic hematopoietic cell transplantation. J Clin Oncol. 2011;29:2230-9. 